\title{
Health Equity Impacts of Medical Tourism in the Caribbean: The Need to Provide Actionable Guidance Regarding Balancing Local and Foreign Interests
}

\author{
L Hoffman $^{1}$, VA Crooks ${ }^{1}$, J Snyder ${ }^{2}$, K Adams ${ }^{2}$
}

\begin{abstract}
Medical tourism is a practice where individuals cross international borders with the intention of privately purchasing healthcare. Caribbean countries are increasingly entering into the medical tourism market, which presents both opportunities and dangers. Our previous fieldwork shows that medical tourism requires host countries to balance the interests of private developers and domestic actors, including those accessing healthcare locally. Discussions with stakeholders in Jamaica, Cayman Islands, Barbados and St Lucia demonstrate concrete instances of this problem. Firstly, medical tourism can enhance training and employment opportunities for domestic health-workers. In doing so, it may exacerbate the inequitable distribution of these workers between the public and private sectors. Secondly, the expansion of private medical services can provide locals with more care options. These facilities may also crowd out existing local operators and price out local consumers. Thirdly, medical tourism is hailed as potentially cross-subsidizing and strengthening the local public health system. It may also heighten health inequities and distract local attention from the needs of the public health sector. Caribbean stakeholders are aware of the promise and dangers of medical tourism. However, they lack clear advice from medical tourism researchers about how to navigate these issues, and specifically balancing local and foreign interests. We call on researchers to shift focus from highlighting the theoretical problems associated with medical tourism to providing concrete guidance to stakeholders in a position to decide whether or not to pursue medical tourism development and to shape this development when it takes place.
\end{abstract}

Keywords: Caribbean, foreign, health equity, medical tourism

WIMJ Open 2015; 2 (3): 142

\section{INTRODUCTION}

Medical tourism occurs when people cross international borders to intentionally pursue private medical treatment, typically paid for out-of-pocket, that may or may not be available at home. Operating outside of formal cross-border care arrangements, this phenomenon has become the subject of intensive cross-disciplinary scrutiny (1-5). While estimates of medical tourist flows continue to be exaggerated through unsubstantiated conjecture (6), academics, researchers and industry representatives agree that medical tourism is indeed a rapid-growth industry (7). Numerous lesserdeveloped countries in particular are touting the perceived local benefits that medical tourism can bring, and are showing serious interest in developing their capacities as

From: ${ }^{1}$ Department of Geography and ${ }^{2}$ Faculty of Health Sciences, Simon Fraser University, Burnaby, British Columbia, Canada.

Correspondence: L Hoffman, SFU Medical Tourism Research Group, Department of Geography, Simon Fraser University, 8888 University Drive, Burnaby, BC V5A 1S6, Canada. E-mail: leonh@sfu.ca medical tourism destinations with the help of offshore foreign investment $(4,6,8)$. The scholarly literature has identified a number of potential benefits and drawbacks that may occur as the result of medical tourism development in lesser-developed countries that can produce implications for health equity, the key findings of which we review throughout this paper.

While the development of medical tourism is commonly located at the intersection of foreign (generally private) and local (including public) interest, and academic curiosity has produced ample literature regarding the sector's potential benefits and drawbacks and their implications for health equity, little actionable guidance is available to countries developing this sector regarding how to balance the interests of foreign and domestic actors as well as determine their relative benefits and drawbacks. Our recent discussions with medical tourism stakeholders in Jamaica, Cayman Islands, Barbados and St Lucia reveal that actors in these countries are well informed of the health equity debates that 
surround medical tourism. Furthermore, our fieldwork has revealed that local and foreign decision-makers alike are keen to obtain guidance from the research community because they find it incredibly complicated to create balance between local and foreign interests in the medical tourism sector, or to determine if and when imbalances are appropriate in order to guard against health inequities. In this succinct viewpoint article, we give examples of these issues and argue that medical tourism researchers should shift their focus on developing actionable guidance to actors within destination countries.

The following sub-sections provide brief examples gathered from our fieldwork in the Anglophone Caribbean of the types of questions that emerge when trying to guard against the negative health equity impacts of developing a medical tourism sector while attempting to strike a meaningful balance between foreign and local interests in destination countries. We present these examples to stimulate discussion and identify new avenues for research pursuit, which is our purpose in writing this viewpoint, as opposed to offering full and comprehensive accounts of the issues at hand. For the sake of brevity, we do not go into detail here about the objectives and analytic findings of our continuing medical tourism research in the Anglophone Caribbean or the methods we have employed since these were reported elsewhere (9-15).

\section{Health human resources}

A commonly discussed potential health equity impact of the establishment of medical tourism in lesser-developed countries is the redistribution of human health resources (11). There is concern that health-workers will be drawn out of the public system to work in private medical tourism clinics, propelled by prospects such as higher salaries and access to better technologies, creating "internal brain drain" (16), as has been seen in Thailand (17). Concurrently, there is also hope for the creation of new employment opportunities in order to retain health-workers domestically (18). It is obvious that an increased demand for medical services by international patients means an increased demand for health human resources. Alongside this, it has been theorized that new employment opportunities as a result of the introduction of medical tourism may stimulate greater numbers of local people to seek out medical training, adding to local knowledge and the sustainability of programmes servicing the public (7).

An example comes from Barbados, where a relatively large, purpose-built medical tourism hospital is currently proposed. The American owner-operators of this hospital propose to staff the facility with physicians from outside Barbados, primarily the United States of America (USA), who can recruit their own patients to be treated in Barbados (15). Although some medical specialities in Barbados are in short supply (eg urologists), others are oversupplied (eg general physicians). In other words, while some local physicians struggle to find work, the vision of the proposed medical tourism hospital is that it will be staffed with international physicians (15). Whose interests are most important to protect in such a case: the international investors who will attract foreign revenue to the country, or the domestic physicians who are underemployed and may gain little from the construction of a new hospital with exclusionary employment practices?

\section{Private healthcare}

For established private healthcare providers in destination countries, an advantage of medical tourism development is the ability for partnership between local clinics and global healthcare organizations (19). This may offer several benefits, including the use of medical technology previously considered too expensive to purchase or local specialists gaining access to training that would typically be undertaken offshore. Further, medical tourism development may enable private hospitals to utilize empty beds not being regularly occupied through local private practice. Filling surplus beds would allow facilities to run closer to capacity and result in revenue increases (18). However, local private healthcare providers may also be negatively affected by the development of medical tourism should such clinics also wish to compete for local private patients or if local patients are eventually priced out of the private market (20).

In St Lucia, representatives of private offshore medical schools targeting North American students indicated that development of a local medical tourism facility would provide them with a training site for their students. It is believed that partnerships with medical tourism facilities would offer them internship positions as well as a wider variety of training opportunities that they would otherwise not be able to provide. What is currently unclear is whether or not private medical tourism facilities would be willing to take on such responsibility. In this case, the private medical schools and their international students would benefit from the existence of a private medical tourism sector treating international patients in the country, while the public benefits of a medical tourism sector in St Lucia are currently unclear. Is this enough of a gain for the country and local citizens to warrant pursuing an expanded medical tourism sector, and especially in light of the fact that many local citizens do not have reasonable access to even basic primary healthcare? This question holds true for Jamaica, where the government suggests that private clinics targeting international patients are actually open to anyone who can afford their care, including locals, even though the majority of local citizens are already priced out of private healthcare, let alone that which is specifically targeting international patients.

\section{Public healthcare}

Public healthcare and public health system transformation are the subjects of much critical debate in the medical tourism literature. It has been suggested that medical tourism 
can positively impact public healthcare through increased access to medical technology (21), a trickle down from foreign exchange that will be re-invested into public health systems (4), and the increased availability of specialists (18). Conversely, negative impacts may include a diminishing attention to public healthcare as a result of optimism toward the high-tech medicine industry, seen as being associated with development and first-world medical practices (21), the growth of a two-tiered health system (18), strain on health human resources (16), and the need to increase public healthcare capital in order to provide higher salaries to retain workers (17).

In the Cayman Islands, there appears to be little local kick-back from medical tourism ventures that have capital, labour and management supplied by foreign interests. A large cardiac hospital for international patients has been recently opened in the country. The domestic government sees this private hospital as a significant healthcare gain for the country as local citizens will no longer need to travel to the USA for cardiac procedures via cross-border care arrangement. Meanwhile, development of this hospital has been undertaken at significant expense to the local environment as it was built on ecologically sensitive land that is home to at least one endangered species (10). Does the potential gain in access to cardiac care for local patients via the private facility owned by overseas investors and heavily staffed by overseas workers override the environmental health equity concerns surrounding its development and loss of a public resource (ie habitat for an endangered species)?

\section{CONCLUSION}

While the above discussion reveals a breadth of potential benefits and drawbacks of medical tourism development and some specific case examples drawn from our fieldwork in the Anglophone Caribbean, it also shows that people in these countries that we have spoken with are aware that medical tourism prospects may positively or negatively impact on health equity. While academics continue to reify the speculative health equity outcomes of sector development, these same individuals want to be able to turn to the academic community for real-world guidance on how best to move forward in balancing local and foreign interests in light of the health equity concerns they hold. It is for this reason that we call for those studying medical tourism to move beyond describing speculative outcomes and health equity impacts and turn their focus toward actionable guidance that can be provided to ground-level stakeholders who are in desperate need of gaining access to resources that can help them balance local and foreign interests, or justify their imbalance. Our purpose here is to put forth this call: it is up to all members of the research community to offer guidance that prioritizes local needs and contexts while working in partnership with local medical tourism stakeholders.

\section{ACKNOWLEDGEMENTS}

This work was supported by multiple Planning Grants awarded by the Canadian Institutes of Health Research. VAC is supported by a Scholar Award from the Michael Smith Foundation for Health Research and holds the Canada Research Chair in Health Service Geographies.

\section{REFERENCES}

1. Casey V, Crooks VA, Snyder J, Turner L. "You're dealing with an emotionally charged individual...": an industry perspective on the challenges posed by medical tourists' informal caregiver-companions. Global Health 2013; 9: 31. doi: 10.1186/1744-8603-9-31.

2. Johnston R, Crooks VA, Snyder J. "I didn't even know what I was looking for": a qualitative study of the decision-making processes of Canadian medical tourists. Global Health 2012; 8: 23. doi: 10.1186/1744-8603-8-23.

3. Noree T, Hanefeld J, Smith R. UK medical tourists in Thailand: they are not who you think they are. Global Health 2014; 10: 29. doi: 10.1186/1744-8603-10-29.

4. Pocock NS, Phua KH. Medical tourism and policy implications for health systems: a conceptual framework from a comparative study of Thailand, Singapore and Malaysia. Global Health 2011; 7: 12. doi: 10.1186/1744-8603-7-12.

5. Turner L. Beyond "medical tourism": Canadian companies marketing medical travel. Global Health 2012; 8: 16. doi: 10.1186/1744-8603-816.

6. Connell J. Contemporary medical tourism: conceptualisation, culture and commodification. Tourism Management 2013; 34: 1-13.

7. Sobo EJ. Medical travel: what it means, why it matters. Med Anthropol 2009; 28: 326-35.

8. Mainil T, Platenkamp V, Meulemans H. The discourse of medical tourism in the media. Tourism Review 2011; 66: 31-44.

9. Adams K, Snyder J, Crooks VA, Hoffman L. Medical tourism in the Caribbean: a call for cooperation. WIMJ Open 2014; 1: 70-3. doi: 10.7727/wimjopen.2014.024.

10. Johnston R, Crooks VA. Medical tourism in the Caribbean region: a call to consider environmental health equity. West Indian Med J 2013; 62: 250-3.

11. Snyder J, Crooks VA, Turner L, Johnston R. Understanding the impacts of medical tourism on health human resources in Barbados: a prospective, qualitative study of stakeholder perceptions. Int J Equity Health 2013; 12: 2. doi: 10.1186/1475-9276-12-2.

12. Snyder J, Crooks VA, Turner L, Johnston R, Fraser H, Kadowaki L et al. Caring for non-residents in Barbados: examining the implications of inbound transnational medical care for public and private health care. In: Pennings G, Botterill D, Mainil T, eds. Medical Tourism and Transnational Health Care. New York: Palgrave MacMillan; 2013: 4863.

13. SFU Medical Tourism Research Group. Jamaica's growing medical tourism sector. Burnaby, Canada: Simon Fraser University; 2014. Available from: http://www.sfu.ca/medicaltourism/One $\% 20$ page $\% 20$ summaries $\% 20 \mathrm{Au}$ gust $\% 202014 /$ Jamaica's\%20Growing\%20Medical\%20Tourism\%20Sec tor.pdf

14. SFU Medical Tourism Research Group. Saint Lucia's medical tourism sector. Burnaby, Canada: Simon Fraser University; 2014. Available from: http://www.sfu.ca/medicaltourism/One\%20page $\% 20$ summaries \%20August $\% 202014 /$ Saint\%20Lucia's\%20Medical\%20Tourism\%20S ector.pdf

15. Johnston R, Crooks VA, Snyder J, Fraser H, Labonté R, Adams K. An overview of Barbados' medical tourism industry - version 2.0. Burnaby, Canada: Simon Fraser University, SFU Medical Tourism Research Group; 2013. Available from: http://www.sfu.ca/medicaltourism/ An\%20Overview\%20of\%20Barbados\%20Medical\%20Tourism\%20In dustry\%20-\%20Version\%202.0.pdf 
16. Smith R, Martínez Álvarez M, Chanda R. Medical tourism: a review of the literature and analysis of a role for bi-lateral trade. Health Policy 2011; 103: 276-82.

17. Medina-Muñoz DR, Medina-Muñoz RD. Critical issues in health and wellness tourism: an exploratory study of visitors to wellness centres on Gran Canaria. Current Issues in Tourism 2013; 16: 415-35.

18. Whittaker A, Manderson L, Cartwright E. Patients without borders: understanding medical travel. Med Anthropol 2010; 29: 336-43.

19. Birch DW, Vu L, Karmali S, Stoklossa CJ, Sharma AM. Medical tourism in bariatric surgery. Am J Surg 2010; 199: 604-8.

20. NaRanong A, NaRanong V. The effects of medical tourism: Thailand's experience. Bull World Health Organ 2011; 89: 336-44.

21. Smith K. The problematization of medical tourism: a critique of neoliberalism. Dev World Bioeth 2012; 12: 1-8.
Received 21 Nov 2014

Accepted 05 Jan 2015

Published 30 Sep 2015

Online: http://www.mona.uwi.edu/wimjopen/article/1645

(C) Hoffman et al 2015.

This is an open access article made freely available under Creative Commons Attribution 4.0 International (CC BY 4.0). Users are free to share, copy and adapt this work as long as the copyright holder (author) is appropriately and correctly credited. See http://creativecommons. org/licences/by/4.0/deed.en_us for more information. 